\title{
The Determination of a Damage Model for Mudstone under Uniaxial Loading in Acidic Conditions
}

\author{
K. Cao, ${ }^{1,2}$ L. Ma $\mathbb{D}^{1},{ }^{1}$ Y. Wu, ${ }^{2}$ A. J. S. (Sam) Spearing, ${ }^{1}$ Naseer Muhammad Khan, ${ }^{1,3}$ and Y. Xie ${ }^{4}$ \\ ${ }^{1}$ School of Mines, China University of Mining and Technology, Xuzhou, 221116 Jiangsu, China \\ ${ }^{2}$ State Key Laboratory for Geomechanics and Deep Underground Engineering, China University of Mining and Technology, Xuzhou, \\ 221116 Jiangsu, China \\ ${ }^{3}$ Department of Mining Engineering, Balochistan University of Information Technology Engineering and Management Sciences, \\ Quetta, Pakistan \\ ${ }^{4}$ Xutuan Mine, Huaibei Coal Mining Group Co., Ltd., Mengcheng, 233500 Anhui, China
}

Correspondence should be addressed to L. Ma; ckma@cumt.edu.cn

Received 29 March 2020; Revised 26 August 2020; Accepted 5 September 2020; Published 8 October 2020

Academic Editor: Wen-Dong Wang

Copyright (c) $2020 \mathrm{~K}$. Cao et al. This is an open access article distributed under the Creative Commons Attribution License, which permits unrestricted use, distribution, and reproduction in any medium, provided the original work is properly cited.

\begin{abstract}
The influence of acid solutions was investigated on the mechanical properties of mudstone. Uniaxial compression tests on mudstone samples were conducted to determine the variations of relative mass, porosity, deformation, and strength characteristics of mudstone subjected to acidic solutions with different $\mathrm{pH}$ values. The change of $\mathrm{pH}$, relative mass, and porosity of mudstone in the process of acid solution immersion was monitored during soaking. The mechanism of hydrochemical corrosion of mudstone samples was preliminarily discussed. The damage parameter was introduced based on the porosity rate. The results show that with increased solution acidity, the peak stress and elastic modulus decreased to different levels, while the peak strain increases in the rock samples. The increased chemical damage parameters reduce the mechanical parameters and increased the deformation parameters. On the basis of the mechanical test, considering the stress-strain relationship of rock in the compaction stage, a segmented damage constitutive model of rock based on chemical damage parameters is established, and the test results are verified. The results show that the correlation coefficient between the theoretical curve and the experimental data is as high as 0.98 , and the model is suitable for the analysis of chemically corroded rock under the uniaxial compression test. The results provide a reference for the analysis and design of coal-bed methane wells where the rocks frequently become acidic during the production of methane.
\end{abstract}

\section{Introduction}

Coal-bed methane (CBM) is a clean and efficient energy source associated with coal seams [1-3]. More than $50 \%$ of China's coal seams are rich in coal-bed methane, with a total of 35 trillion $\mathrm{m}^{3}$ of coal-bed methane in the mines, which is the third largest coal-bed methane storage in any country after Russia and Canada. During the process of coal-bed methane well drainage and gas production, the groundwater continuously changes into acidic or alkaline water [4-7]. The coal and rock of the reservoir are affected due to this corrosion. The hydrochemical solution produces pore water pressure, which reduces the effective stress that the rock skeleton can bear, thus reducing the effective strength of the rock. Furthermore, a hydrochemical solution has certain adverse chemical effects on the mineral composition of the rock and the cementing properties between the mineral particles. This chemical effect plays a significant role in changing the original structure of the rock and can even produce new minerals [8-11]. This in turn affects the process of desorption, diffusion, and seepage interaction of coal-bed methane in the reservoir. Whether coal-bed methane can produce gas and whether it can produce high productive yield depends on the degree and range of desorption of coal-bed methane [4]. Therefore, it is of great significance to study the physical and mechanical properties of the rock corroded by chemical water in order to ensure the efficient exploitation of coal-bed methane. 
In recent years, much progress has been made in understanding the influence of hydrochemical solutions on rock mechanical properties. Tang et al. [12] studied the rock mechanics and environmental effects under the action of hydrochemistry and obtained the results of a three-point bending test and uniaxial rock compression test under the action of different hydrochemistry solutions. Feng and Ding [13] studied the characteristics of crack propagation of prefabricated rock samples under various chemical solution corrosion and uniaxial compression conditions by using the independently developed stress-percolation-chemical coupling mechanics system. Wang et al. [11] carried out corrosion tests on sandstone under the action of different $\mathrm{pH}$ aqueous chemical solutions. The type and degree of waterrock chemical interaction in different aqueous chemical environments are different, which leads to different changes in the microstructure of rock. The neutral solution loss of cementing materials in rock and large-size mineral aggregates in the acid solution would also undergo a lot of dissolution. Ding et al. [14] carried out dissolution kinetic experiments and analysis on rocks soaked in different aqueous chemical solutions, analyzed the dissolution characteristics of rocks in different aqueous chemical solutions, and obtained the corresponding erosion dissolution kinetics equations. Li et al. [15] and Xu et al. [16] conducted shear tests on the mudstone corroded by chemical solution. They studied the influence of hydrochemical solution on the shear strength of mudstone, established the relationship between porosity and shear strength index, and obtained the influenced role of chemical solution corrosion on the crack opening, failure, and expansion direction of mudstone. Han et al. [17] carried out wave velocity tests and conventional triaxial compression tests on mudstones corroded by aqueous chemical solution with different electrolyte $\mathrm{pH}$ values, compositions, and varying concentrations of calcium and magnesium ions in the solution. He concluded that the decrease of mechanical properties of mudstones after chemical corrosion was closely related to the change of porosity.

The study of the mechanical properties of rock can provide a basis for the design of rock excavations, while the construction of the constitutive rock model can provide a theoretical basis for the prediction of the stability of the rock. In terms of the constitutive rock model, Kang [18] analyzed the influence of water on rock strength and deformation based on damage mechanics. They used the volume change caused by rock dilitancy to characterize damage variables and established the evolution equation of damage variables for saturated rock. Hu et al. [19] analyzed the influence of water on the mechanical properties of rock under uniaxial compression and deduced the statistical model of rock damage considering the influence of water content. Based on the Weibull distribution, Zhang et al. [20] established a statistical damage constitutive model that can reflect multiple test curves by using the relationship between peak strength and elastic modulus in addition to the relationship between water content and rock damage constitutive model parameters. Chen et al. [21] based on the principle of effective stress assumed that the damage of rock was caused by the effective stress of particles and the effective stress of body structure.
According to the condition of stress balance, the stress relation equation under the two effective stresses is obtained, and on this basis, the damage evolution equation of saturated rock under uniaxial compression is established.

The constitutive damage models of rock established in the past however only consider the influence of water content, and the constitutive damage model of rock after chemical solution corrosion was seldom reported. Due to the corrosion of a chemical solution, the initial compaction stage of the rock stress-strain curve is more significant. The compaction stage of stress-strain curve drawn by the traditional statistical damage constitutive model is quite different from the experimental curve. In this paper, the mechanical properties of mudstone after chemical corrosion were analyzed. Chemical damage parameters were introduced to quantitatively characterize the mechanical parameters of rocks, and the compaction stage and subsequent stage were innovatively expressed separately. This allowed a rock segmental damage statistical constitutive model with chemical damage parameter interface to be built. The research results are expected to enrich the rock mechanics theory of underground engineering and provide a theoretical reference for the more efficient mining of coal-bed methane.

\section{Experimental Design}

2.1. Preparation of Acidic Solutions. The complex composition of water ions in nature makes it impossible to consider the effects of all the various ions on rocks. Considering the high content of $\mathrm{Na}^{+}, \mathrm{K}^{+}$, and $\mathrm{Cl}^{-}$ions typically found in groundwater therefore, a solution of $\mathrm{NaCl}$ and $\mathrm{KCl}$ was selected as the electrolyte solute to configure the hydrochemical solution [11]. The mine water collected from the rock is mainly acidic, with a $\mathrm{pH}$ range of 2.0-6.5; therefore, this research considers mostly the influence of the acidity of the solution on the rock characteristics and properties. The interaction between water and rock is a slow process in situ, so due to time constraints, four different acidic solutions with high solution concentration and increasing the $\mathrm{pH}$ value were selected. This was to reflect the water chemistry and solution corrosion effect in a relatively short time on the mudstone samples. The chemical solutions prepared for this research are shown in Table 1. Electrolyte solutions with $\mathrm{pH}$ values of $1.3,3.3,5.3$, and 7.3 with a concentration of $0.1 \mathrm{~mol} / \mathrm{L}$ $\mathrm{NaCl}$ and $\mathrm{KCl}$ were used in this research experiment. The $\mathrm{pH}$ value of the acid solution was adjusted by adding $68 \%$ $\mathrm{HNO}_{3}$ into the mix. The procedure was first to add $\mathrm{NaCl}$ and $\mathrm{KCl}$ into the distilled water, stir with a glass rod to make it fully dissolved, then take $68 \% \mathrm{HNO}_{3}$, dilute with $100 \mathrm{ml}$ distilled water, and add it to the electrolyte solution drop by drop. During the gradual acid introduction, a $\mathrm{pH}$ meter was used to monitor the $\mathrm{pH}$ change of the solution in real time until the predetermined $\mathrm{pH}$ value was reached.

2.2. Sample Preparation. The representative sandy mudstone samples collected from a coal mine in Shandong Province, China, were used in this research study. The X-ray diffractometer was used for the mineralogical composition of representative samples. The result shows quartz (35.7\%), feldspar 
TABLE 1: Preparation of chemical solutions.

\begin{tabular}{lcccc}
\hline Group & $\begin{array}{c}\text { Solution } \\
\text { type }\end{array}$ & $\begin{array}{c}\text { Solution } \\
\text { composition }\end{array}$ & $\begin{array}{c}\text { Solution } \\
\text { concentration } \\
(\mathrm{Mol} / \mathrm{L})\end{array}$ & $\begin{array}{c}\mathrm{pH} \\
\text { value }\end{array}$ \\
\hline $\mathrm{A}$ & $\begin{array}{c}\text { Acidic } \\
\text { solution } \\
\text { B }\end{array}$ & $\mathrm{NaCl}, \mathrm{KCl}$ & 0.1 & 1.3 \\
$\mathrm{C}$ & $\begin{array}{c}\text { Acidic } \\
\text { solution } \\
\text { Acidic } \\
\text { solution }\end{array}$ & $\mathrm{NaCl}, \mathrm{KCl}$ & 0.1 & 3.3 \\
$\mathrm{D}$ & $\begin{array}{c}\text { Neutral } \\
\text { solution }\end{array}$ & $\mathrm{NaCl}, \mathrm{KCl}$ & 0.1 & 5.3 \\
\hline
\end{tabular}

(16.3\%), calcite $(6.4 \%)$, dolomite $(4.2 \%)$, mica $(3.4 \%)$, and clay mineral content $(34 \%)$. The main mineral composition was kaolinite, illite, chlorite, and carbonate.

The rock samples were collected from the mine at the same location. The core was extracted from the same block of mudstone to keep similar and uniformed mechanical properties and minimize any mineralogical and size effect. The prepared rectangular-sized specimens had precise dimensions of $50 \times 50 \times 100 \mathrm{~mm}$. The edge angles were kept strictly at $90^{\circ}$ to ensure that the lateral pressure could be loaded smoothly and evenly on the rock sample sides. The nonparallelism of the two ends of the test piece was less than $0.005 \mathrm{~mm}$, and the grinding flatness of the end face was less than $0.02 \mathrm{~mm}$. A total of 20 samples were prepared and divided into five groups: A, B, C, D, and E. E group samples were kept completely dry as a control.

The size and weight of the finished samples were recorded after vacuumed and dried for $48 \mathrm{hrs}$ at $108^{\circ} \mathrm{C}$. The rock sample from groups $\mathrm{A}, \mathrm{B}, \mathrm{C}$, and D was soaked in each chemical solution, as described in Table 1. In order to reduce the dispersion of experimental data, and the peak strength of each group of rock samples is removed from the one that deviates from the average value. Therefore, a total of 15 rock samples left having three specimens from each group were used for subsequent data analysis.

2.3. Experimental Procedure. In this research, the previous experimental research procedure was followed [11]. 1.5 litres of each $\mathrm{pH}$ solution was used for each sample. It was found that the $\mathrm{H}^{+}$in the solution having $\mathrm{pH} 3.3$ and 5.3 was consumed by chemical reaction with the minerals in the rock, after the rock sample was soaked for about 30 days. Therefore, all rock samples were soaked for 30 days in a full immersion solution container in an open environment. The samples were immersed in the solution and regularly agitated to reflect the real occurrence environment of rock. During the soaking of the samples, the solution pH and rock samples' mass and porosity samples' change were noted. The $\mathrm{pH}$ of the solution and rock mass were measured every two hours in the early stage and once daily when it reached a stable stage. During the soaking process, the measurement interval was based on the change rate of the $\mathrm{pH}$ value of the solution. It is considered that the water-rock interaction reached a steady state when the change of the $\mathrm{pH}$ value remained stable for a period of time. All rock samples were tested using the conventional uniaxial loading method with the displacement rate of $0.1 \mathrm{~mm} / \mathrm{min}$, after soaking.

\section{Experiment Results}

\subsection{Interaction between the Hydrochemical Solution and Mudstone}

3.1.1. $\mathrm{pH}$ Change of Solution. The $\mathrm{pH}$ value of the solution was monitored over time during the experiment, as shown in Figure 1. With the neutral solution having $\mathrm{pH}=7.3$, the $\mathrm{pH}$ value increased slowly with soaking time and then remained constant. With the acidic solution having $\mathrm{pH}=$ $5.3, \mathrm{pH}$ showed a trend of rapid increase, slow growth, and stable with the increase of soaking time. The $\mathrm{pH}$ value began to increase to 6.8 from 0 to 115 hours, and then slowly increased to 7.7 from 115 to 591 hours, and then became stable and remained constant. With the solution having $\mathrm{pH}=$ 3.3 , the $\mathrm{pH}$ value increased with the increase of soaking time and reached $\mathrm{pH}$ value to 7.4 maximum, and the solution was stable with soaking time 720 hours. The $\mathrm{pH}$ value of the solution with $\mathrm{pH}=1.3 \mathrm{had}$ almost no change with the increase of immersion time, because the content of $\mathrm{H}^{+}$in the solution with $\mathrm{pH}=1.3$ was more, and only a small proportion of $\mathrm{H}^{+}$ is consumed when a chemical reaction occurs with rocks. When the $\mathrm{pH}$ is 3.3 and 5.3 solutions begin to soak, the $\mathrm{pH}$ shows a rapid growth trend. This is because the concentration of $\mathrm{H}^{+}$in the initial stage of rock soaking was high, and the chemical reaction rate was fast. With the increase of soaking time, the concentration of $\mathrm{H}^{+}$decreases, resulting in the slow chemical reaction rate.

3.1.2. Change of Masses of Mudstone Samples. In the process of soaking, the samples were taken out every day; sample surface water was wiped with a cotton cloth to make it free of surface liquid. The sample was placed in a dry location for 5 minutes to ensure that the liquid on the surface of the sample volatilizes completely and then weighed on an electronic scale. According to the difference between the measured mass and the initial mass of the sample, the relative mass change rate of the sample at different times is $[11,17]$

$$
\omega=\frac{m-m_{\mathrm{NS}}}{m_{\mathrm{NS}}} \times 100 \%,
$$

where $m_{\mathrm{NS}}$ and $m$ are the mass of the sample in the initial state and after soaking condition, respectively.

Figure 2 shows the curve of the change rate of the relative mass of the sample with the immersion time, which indirectly reflects the degree of water-rock interaction. As observed from Figure 2, the relative mass change rate of the soaked samples in the solution with $\mathrm{pH}=7.3, \mathrm{pH}=5.3, \mathrm{pH}$ $=3.3$, and $\mathrm{pH}=1.3$ increases rapidly at the initial stage of immersion. Thus, the water absorption on the rock surface at the initial stage of immersion is much higher than the mineral consumption due to chemical reaction. After a prolonged soaking time, samples in an acid solution having $\mathrm{pH}$ 5.3, 3.3, and 1.3 show a decreased trend while samples having $\mathrm{pH}=7.3$ show an increasing trend due to the neutral 


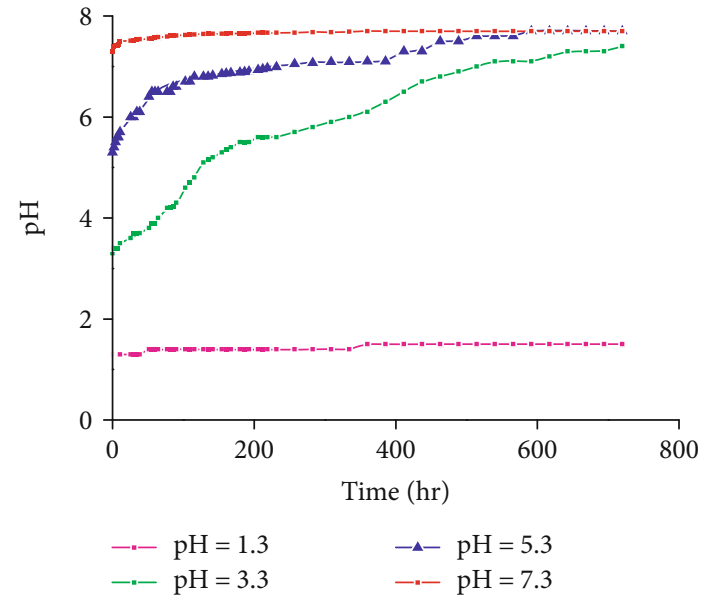

FIGURE 1: $\mathrm{pH}$ value of solution with time.

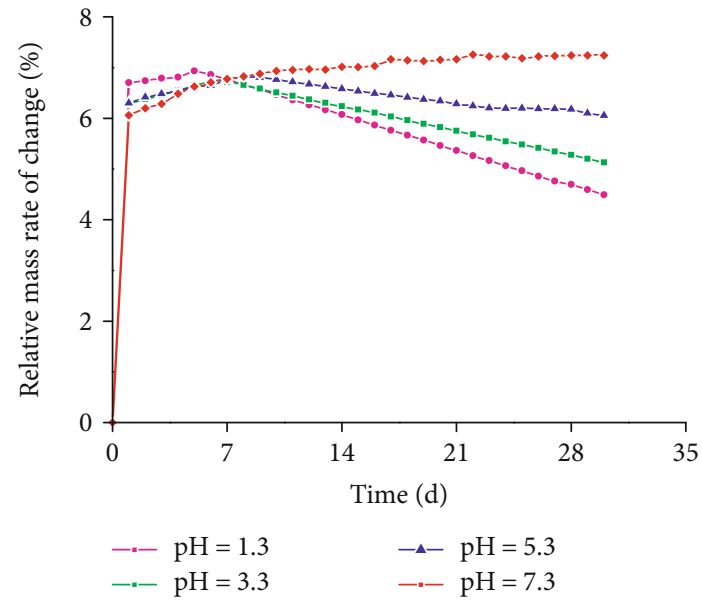

FIGURE 2: Change rate of relative mass of sample with soaking time.

solution; no chemical reaction occurred with rock mineral. Initially, during the soaking of samples, solution diffusion was dominant in the acid rock reaction, and water absorption increased the mass of the samples. During prolonged soaking, the rock samples are saturated, and chemical corrosion plays an active role. The mudstone mineral components are hydrolyzed and dissolved, which decreased the mass of the sample. The relative mass change rate of samples in $\mathrm{pH}=$ $5.3,3.3$, and 1.3 solutions show a downward trend, and the lower the $\mathrm{pH}$ value is, the faster the decline speed. The trends show that the stronger the acidity of the solution, the stronger the reaction between the sample and the solution, and the faster the corrosion rate.

3.1.3. Porosity. Mudstone is a porous medium with microcracks and pores. The porosity of the sample in this experiment is its total porosity (including two parts of open and closed pores), and the calculation formula is [17]

$$
n=\left(1-\frac{\rho_{g}}{\rho}\right) \times 100 \%
$$

where $n$ is the total porosity of the specimen, $\rho_{\mathrm{g}}$ is the bulk density of the specimen, and $\rho$ is the particle density of the specimen.

The bulk density is determined by the following formula:

$$
\rho_{\mathrm{g}}=\rho_{V} \times \frac{m_{0}}{m_{1}-m_{2}},
$$

where $m_{0}$ is the mass of the dry sample in air $(\mathrm{g}), m_{1}$ is the mass of the saturated sample in air (g), $m_{2}$ is the mass of the saturated sample in water $(\mathrm{g})$, and $\rho_{\mathrm{v}}$ is the density of water at room temperature $\left(\mathrm{g} / \mathrm{cm}^{3}\right)$.

When testing the total porosity before corrosion, the dried rock samples of groups A-D were tested in the air first and then soaked in water for 14 days to test the mass of rock samples in the air and water, respectively. Finally, the rock samples of groups A-D are baked in a dryer for 48 hours, cooled naturally to room temperature, and soaked in chemical solution.

The particle density is determined by the following formula:

$$
\rho=\rho_{V} \times \frac{m_{3}}{m_{4}+m_{3}-m_{5}}
$$

where $m_{3}$ is the mass of rock powder in the air $(\mathrm{g}), m_{4}$ is the mass of a density bottle containing distilled water (g), and $m_{5}$ is the mass of a density bottle containing rock powder and water $(\mathrm{g})$.

Three parts of rock powder are produced by rolling the fragments of dry rock samples under uniaxial loading, and the average of the three parts of rock powder particle density is taken as the particle density of rock.

In this paper, the porosity rate reflects the variations of porosity in the mudstone specimens; the calculating formula is [17]

$$
\eta=\frac{n_{t}-n_{0}}{n_{0}} \times 100 \%
$$

where $n_{0}$ and $n_{t}$ is the total porosity of the specimen before and after corrosion, respectively.

Table 2 shows the statistics of porosity and porosity change rate of mudstone before and after corrosion. The porosity change rate of group A is $7.77 \%$, group B is $6.27 \%$, group C is $4.38 \%$, and group D is $1.89 \%$. Furthermore, the rate of porosity increased with acidity, which shows porosity is strongly influenced by acidity. The porosity change rate of group A is 4.11 times than that of group D.

3.2. Mechanical Properties. The comparison of the results of the parallel tests revealed that the prepeak stress-strain curves of each group of three tests have a good similarity. The postpeak stress-strain curves of the three tests are different due to the differences of the individual samples, showing a particularly distinct type. The main mechanical parameters of rock samples are determined by the stress-strain prepeak curve, so it can be considered that the uniaxial loading test of mudstone soaked by acid water is repeatable. 
TABLE 2: Rock porosity and chemical damage parameters.

\begin{tabular}{lcccc}
\hline $\begin{array}{l}\text { Sample } \\
\text { number }\end{array}$ & $\begin{array}{c}\text { Initial } \\
\text { porosity } \\
(\%)\end{array}$ & $\begin{array}{c}\text { Porosity after } \\
\text { corrosion } \\
(\%)\end{array}$ & $\begin{array}{c}\text { Rate of } \\
\text { porosity } \\
\text { change }(\%)\end{array}$ & $\begin{array}{c}\text { Chemical } \\
\text { damage } \\
\text { parameter }(\%)\end{array}$ \\
\hline $\mathrm{A}_{1}$ & 15.74 & 16.95 & 7.69 & 1.44 \\
$\mathrm{~A}_{2}$ & 16.01 & 17.24 & 7.68 & 1.47 \\
$\mathrm{~A}_{3}$ & 15.88 & 17.14 & 7.94 & 1.50 \\
$\mathrm{~B}_{1}$ & 16.33 & 17.38 & 6.43 & 1.25 \\
$\mathrm{~B}_{2}$ & 15.92 & 16.92 & 6.28 & 1.19 \\
$\mathrm{~B}_{3}$ & 16.04 & 17.02 & 6.11 & 1.17 \\
$\mathrm{C}_{1}$ & 16.21 & 16.93 & 4.44 & 0.85 \\
$\mathrm{C}_{2}$ & 15.85 & 16.56 & 4.48 & 0.84 \\
$\mathrm{C}_{3}$ & 16.08 & 16.76 & 4.23 & 0.81 \\
$\mathrm{D}_{1}$ & 15.77 & 16.07 & 1.90 & 0.36 \\
$\mathrm{D}_{2}$ & 15.80 & 16.12 & 2.03 & 0.38 \\
$\mathrm{D}_{3}$ & 16.17 & 16.45 & 1.73 & 0.33 \\
\hline
\end{tabular}

The stress-strain curve of mudstone after soaking in acid water is shown in Figure 3. It includes the loading processes of all rock samples' progress through four stages: compaction, elastic, plastic (stable crack propagation and unstable crack propagation), and postpeak. As the acidity of the solution increases, the range of the stress-strain curve in the compaction stage increases, the range of the elastic stage decreases, and the plastic stage becomes more significant. In this paper, "axial stress method" is used to analyze the proportion of the compression stage of the specimen after immersion in acid water from the stress-strain curve before peak stress. Several points are selected in the straight-line section (linear elastic deformation stage) of the stress-strain curve, and the best fitting straight line of the linear elastic deformation stage is obtained. Since the slopes of the compaction stage and the elastic stage are different, the bifurcation point of the fitting line and the stress-strain curve is defined as the endpoint of the compaction stage as shown in Figure 4, and the corresponding stress value is the compaction stress [22]. The crack initiation stress and crack damage stress are determined by the crack volume strain curve and the volume strain curve, respectively [23-25]; the volumetric strain calculation formula is as follows:

$$
\varepsilon_{v}=\varepsilon_{1}+2 \varepsilon_{2}
$$

where $\varepsilon_{v}$ is the volumetric strain, $\varepsilon_{1}$ is the axial strain, and $\varepsilon_{2}$ is the lateral strain.

The crack volume strain of the rock will change due to the crack deformation in the process of the primary microcrack closing and expanding and then new crack initiation and development. For rock under uniaxial loading, the formula of crack volume strain can be expressed as follows:

$$
\varepsilon_{v e}=\varepsilon_{v}-\frac{1-2 \mu}{E} \sigma_{1}
$$

where $\varepsilon_{v e}$ is the crack volume strain, $\sigma_{1}$ is the axial stress, $\mu$ is the Poisson ratio, and $E$ is the elastic modulus.

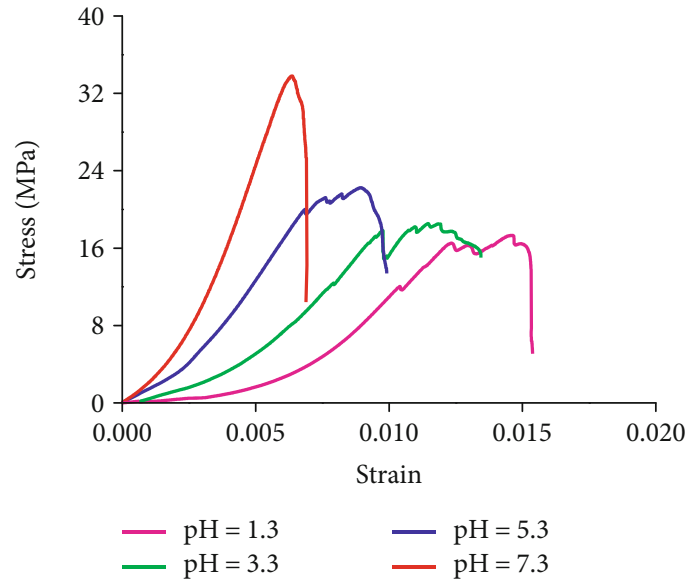

FIgURE 3: Stress strain of rock after soaking at different $\mathrm{pH}$.

Figure 4 shows the evolution curve of rock volume strain and crack volume strain, in which the turning point of the crack volume strain from rising to horizontal is the end point of compaction stage, the turning point from horizontal to falling is the crack initiation point, and the turning point of volume strain curve from rising to falling is the crack damage point.

The ratio of compaction stress to peak stress of each specimen is shown in Table 3. According to Table 3, the ratio of the rock compaction stress to peak stress decreases with the increase of $\mathrm{pH}$. The average ratio of compaction stress to peak stress in groups: $\mathrm{A}$ is $0.378, \mathrm{~B}$ is $0.333, \mathrm{C}$ is $0.314, \mathrm{D}$ is 0.305 , and $\mathrm{E}$ (control group) is 0.253 . The results revealed that acidity significantly increases the proportion of rock compaction stage.

The three kinds of mechanical parameters of mudstone soaked in acid water were obtained from the uniaxial compressive test data. These parameters were peak stress, elastic modulus, and peak strain. The trend of peak stress, peak strain, and modulus of elasticity of rock with $\mathrm{pH}$ is shown in Figures 5-7. The peak stress and elastic modulus linearly have a positive correlation with $\mathrm{pH}$ variation, while peak strain and $\mathrm{pH}$ have a linearly negative correlation. When $\mathrm{pH}$ increased by 1 , the peak stress and elastic modulus increased by $2.21 \mathrm{MPa}$ and the $0.96 \mathrm{GPa}$, respectively, while the peak strain decreased by 0.0016 .

The mechanical properties of mudstone change with the changes in the $\mathrm{pH}$ value of the acid solution. At the same time, the acid solution will also affect the macroscopic failure pattern of mudstone. The failure patterns of mudstone samples were recorded by photographing, and the failure patterns were sketched. Due to the space limitation, a typical rock sample was selected for analysis in each group. Figure 8 shows the failure pattern and sketch of mudstone under uniaxial loading after soaking in acid solution. As shown in Figure 8, rock samples $C_{2}$ and $D_{1}$ were damaged by a single tensile crack. Two main tensile cracks appeared on the surface of the rock sample $A_{3}$, with the bifurcation cracks distributed in the area near the main crack, and shear cracks appeared in the upper area of the rock sample. The rock sample $B_{2}$ is shear failure, and two tensile cracks 


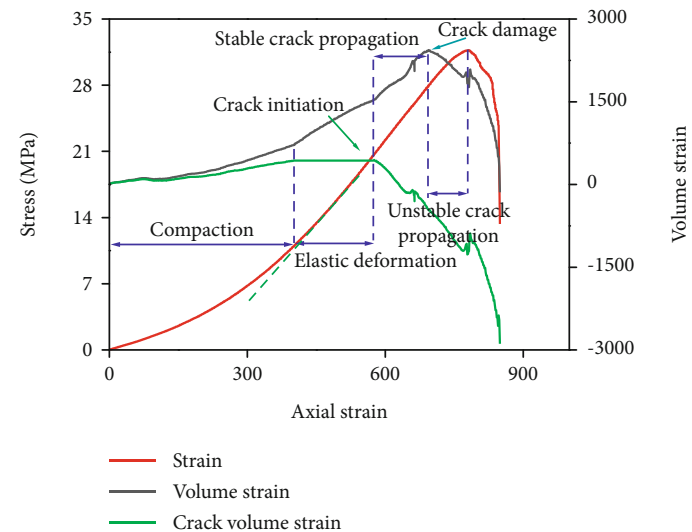

Figure 4: The curve of volumetric strain and crack volumetric strain of rock.

TABLE 3: Rock mechanical parameters.

\begin{tabular}{lccccc}
\hline $\begin{array}{l}\text { Sample } \\
\text { number }\end{array}$ & $\begin{array}{c}\text { Peak } \\
\text { stress } \\
(\mathrm{MPa})\end{array}$ & $\begin{array}{c}\text { Peak } \\
\text { strain }\end{array}$ & $\begin{array}{c}\text { Compressive } \\
\text { stress (MPa) }\end{array}$ & Ratio & $\begin{array}{c}\text { Elastic } \\
\text { Modulus } \\
(\mathrm{GPa})\end{array}$ \\
\hline $\mathrm{A}_{1}$ & 17.33 & 0.0146 & 6.92 & 0.399 & 2.11 \\
$\mathrm{~A}_{2}$ & 18.61 & 0.0177 & 6.91 & 0.371 & 2.31 \\
$\mathrm{~A}_{3}$ & 17.51 & 0.0153 & 6.37 & 0.364 & 1.92 \\
$\mathrm{~B}_{1}$ & 21.59 & 0.0119 & 7.99 & 0.370 & 3.64 \\
$\mathrm{~B}_{2}$ & 21.54 & 0.0118 & 7.09 & 0.329 & 3.06 \\
$\mathrm{~B}_{3}$ & 22.11 & 0.0123 & 6.61 & 0.299 & 3.40 \\
$\mathrm{C}_{1}$ & 26.87 & 0.00896 & 9.30 & 0.346 & 5.69 \\
$\mathrm{C}_{2}$ & 27.01 & 0.0090 & 8.18 & 0.303 & 4.60 \\
$\mathrm{C}_{3}$ & 26.25 & 0.00896 & 7.69 & 0.293 & 4.79 \\
$\mathrm{D}_{1}$ & 30.41 & 0.00613 & 8.48 & 0.279 & 8.07 \\
$\mathrm{D}_{2}$ & 31.70 & 0.00638 & 10.4 & 0.328 & 7.68 \\
$\mathrm{D}_{3}$ & 30.77 & 0.00609 & 9.48 & 0.308 & 8.22 \\
$\mathrm{E}_{1}$ & 50.14 & 0.00498 & 10.6 & 0.211 & 10.5 \\
$\mathrm{E}_{2}$ & 43.28 & 0.00537 & 12.5 & 0.288 & 9.87 \\
$\mathrm{E}_{3}$ & 46.97 & 0.00521 & 12.2 & 0.259 & 9.93 \\
\hline
\end{tabular}

appeared near the main shear crack. In other words, the number of cracks in the process of rock failure increases with the increase of acidity, and the failure pattern tends to be complex. This is due to the stress concentration that occurred around the pores and microcracks during the crack stable development stage of rock, which will cause the pores and microcracks to generate new cracks and stably expand. The acid solution will increase the porosity of mudstone and then promote the formation of more new cracks and stable propagation of microcracks. In the crack unstable development stage of rock, more microcracks will expand irregularly, and the deformation will be more complex and severe. When the microcracks gather to form the local weakening of macro critical scale, more microcracks will be generated on the rock surface. Therefore, with the increase of acidity, the number of cracks after rock failure increases and hence, the failure morphology tends to be more complex, and the peak strain increases.

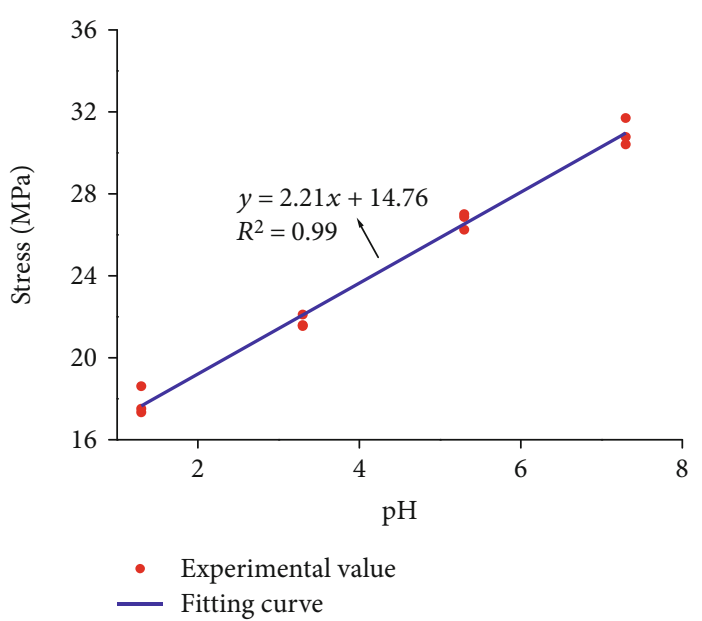

FIgURE 5: Variation trend of peak stress with $\mathrm{pH}$.

\section{Constitutive Model Development}

4.1. Chemical Corrosion. The mudstone damage caused by chemical corrosion is mainly due to the dissolution of soluble cementitious materials and chemical reactions within the mineral composition. The chemical corrosion correspondingly changes the microstructure of mudstone continuously and causes damage, which reduces the mechanical properties of mudstone. In this paper, porosity is selected as a parameter representing damage. Porosity reflects the corrosion damage degree of solution chemical corrosion to mudstone. The selected chemical damage parameter, $D_{\mathrm{ch}}$, is calculated as follows [17]:

$$
D_{c h}=\left(1-\frac{1-n_{t}}{1-n_{0}}\right) \times 100 \%
$$

where $n_{t}$ is the porosity after chemical corrosion and $n_{0}$ is the porosity before chemical corrosion.

The microstructure and mineral composition of mudstone samples were changed to different degrees after corroded by an aqueous chemical solution. The corrosion caused damage to the samples and resulted in the macroscopic mechanical parameters of the samples to decrease. According to Equation (8), the corresponding chemical damage variable $D_{\mathrm{ch}}$ of mudstone samples after corrosion by an acidic solution is calculated, and the relationship between $D_{\mathrm{ch}}$ and physical mechanical parameters of mudstone samples is obtained. The fitting curve results are shown in Figures 9-11.

The peak strength and elastic modulus of mudstone samples decreased with the increase of damage variables, while the peak strain increases with the increase of damage variables. Furthermore, acidity affects the macroscopic physical and mechanical parameters of mudstone samples and decreases with the increase of acidity. The deformation parameters however increased with the increase of acidity. Based on the results, therefore, the relationships between peak strength, peak strain, elastic modulus, and chemical damage parameter were fitted by using the first-order 


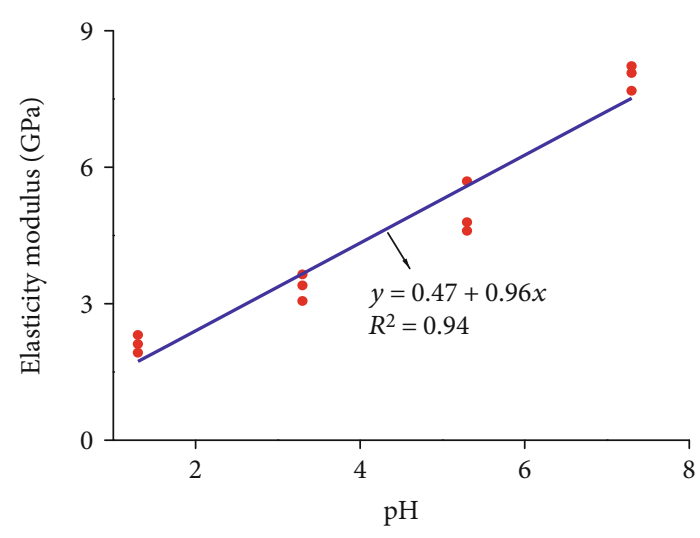

- Experimental value — Fitting curve

FIGURE 6: Variation trend of elastic modulus with $\mathrm{pH}$.

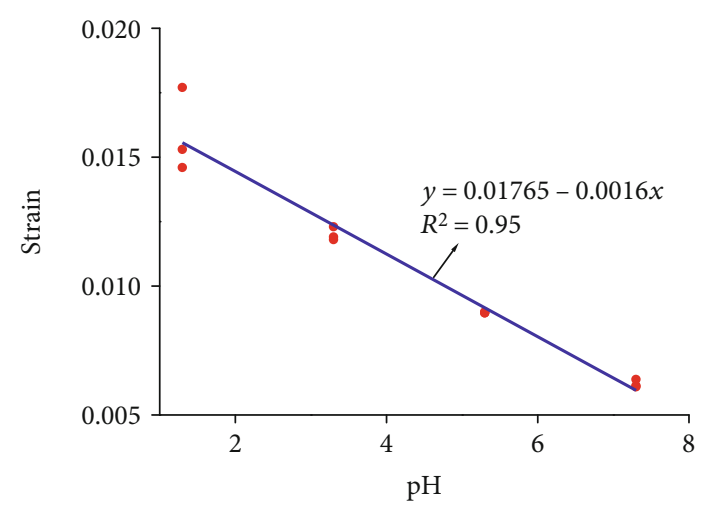

- Experimental value

— Fitting curve

Figure 7: Variation trend of peak strain with $\mathrm{pH}$.
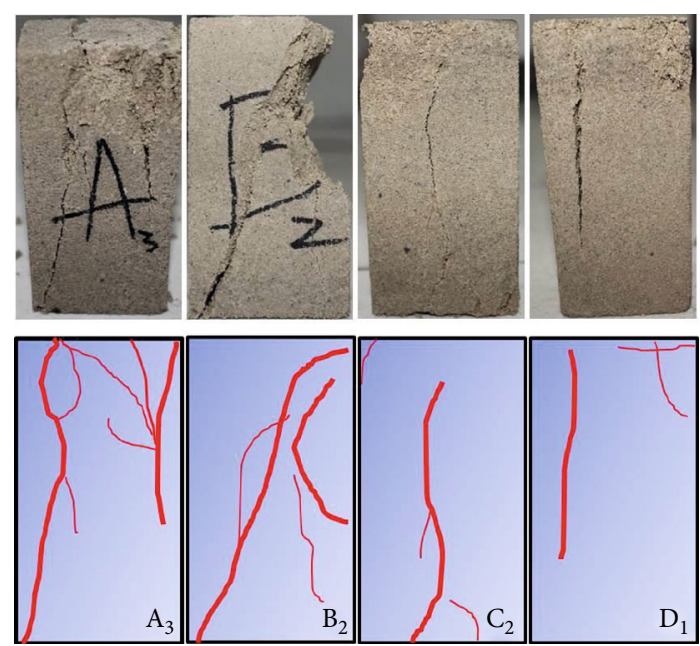

Figure 8: Failure pattern and sketch of mudstone under uniaxial loading after acidic solution corrosion.

function relationship, and all of them had a good fitting degree with a correlation coefficient from 0.92 to 0.97 . The expressions of mudstone peak strength, peak strain, elastic

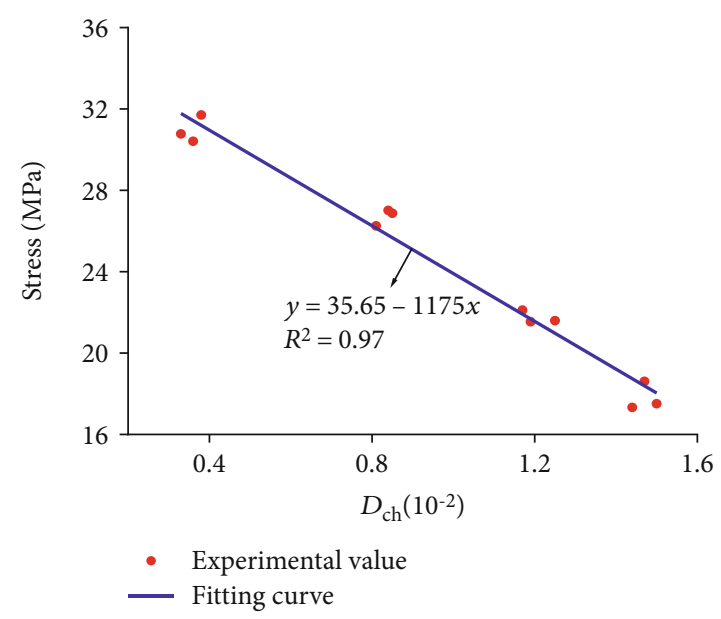

FIGURE 9: Chemical damage parameters and peak stress.

modulus, and chemical damage parameters $D_{\mathrm{ch}}$ after soaking in acid water are as follows:

$$
\left\{\begin{array}{l}
\sigma_{c}=a-b D_{\mathrm{ch}}, \\
\varepsilon_{c}=c+d D_{\mathrm{ch}}, \\
E=e-f D_{\mathrm{ch}} .
\end{array}\right.
$$

4.2. Damage Variables under Stress. According to the equivalent strain hypothesis proposed by Lemaitre [26], the effective stress is equal to the deformation of the damaged material; that is, the strain caused by the stress of rock is equivalent to the strain caused by the effective stress of rock without damage. It is only necessary to replace the nominal stress with the effective stress, and the constitutive damage equation of the rock is

$$
[\sigma]=\left[\sigma^{*}\right](I-[D])=[H][\varepsilon](I-[D]),
$$

where $[\sigma]$ and $[\sigma *]$ are nominal stress and effective stress, respectively, $I$ is the identity matrix, $[D]$ is the damage variable matrix, $[H]$ is the elastic modulus matrix, $[\varepsilon]$ is the strain matrix. Assuming that rock damage is isotropic, the onedimensional damage constitutive relation of rock can be expressed as

$$
\sigma=\sigma^{*}(1-D)=E \varepsilon(1-D),
$$

where $D$ is the damage variable.

From the above, the compaction stage of uniaxial stressstrain curve of rock under acid water immersion can be clearly identified, and the proportion of compaction increases with the increase of acidity. The traditional continuous damage constitutive model does not consider the compaction stage of rock. Therefore, in this paper, the uniaxial compressive stress-strain curve of rock soaked in acid water is divided into the compaction stage and subsequent damage expansion stage, and therefore, a separate damage constitutive model is established. 


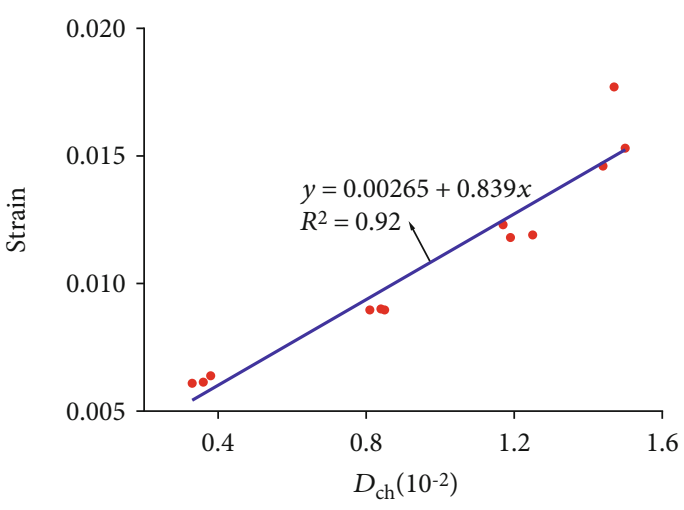

- Experimental value

— Fitting curve

FIgURE 10: Chemical damage parameters and peak strain.

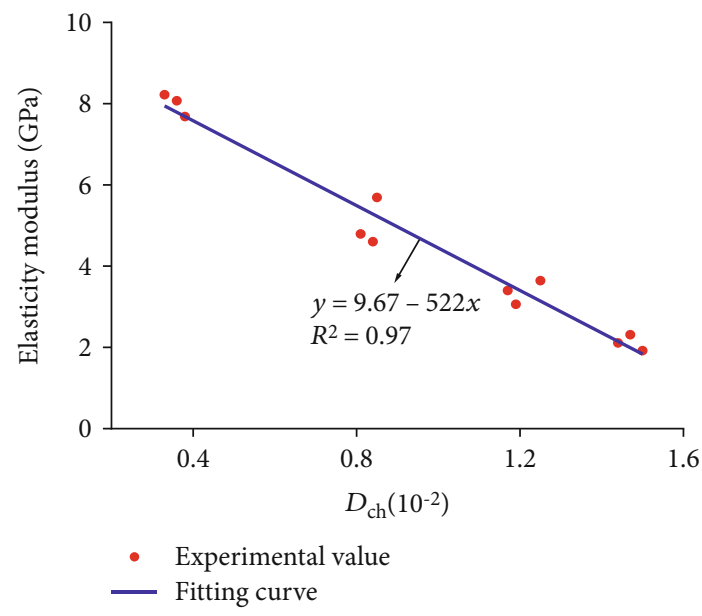

Figure 11: Chemical damage parameters and elastic modulus.

It is assumed that the pores and fissures of the rock are compacted in the compaction stage without damage expansion, and continuous damage occurs in the elastic (linear), plastic, and postpeak stages. According to the results of Lu's research [27], the stress-strain relationship in the rock compaction stage can be expressed as

$$
\sigma=\sigma_{A}\left(\frac{\varepsilon}{\varepsilon_{A}}\right)^{2}
$$

where $\sigma$ is stress and $\varepsilon$ is strain, in the process of uniaxial loading, while $\sigma_{\mathrm{A}}$ is the maximum stress and $\varepsilon_{\mathrm{A}}$ is the maximum strain in the compaction stage.

The rock material is heterogeneous and contains a variety of defects, which greatly affect mechanical properties. The distribution of defects is random, so the resuling damage is also distributed randomly in the rock material. It can therefore be considered that the rock strength is a random variable. Weibull distribution is used to describe the law of random statistical distribution of rock strength, so the probability density function of the failure of microelements of rock material is $[28,29]$

$$
P(F)=\frac{m}{F}\left(\frac{\mathcal{E}}{F}\right)^{m-1} \exp \left[-\left(\frac{\mathcal{E}}{F}\right)^{m}\right]
$$

where $m$ and $F$ are two constants, characterizing the brittleness (nonuniformity) of materials, reflecting the different response characteristics of rock materials to external loads, and both are nonnegative numbers. $F$ is the random distribution variable of the microelement intensity, $m$ is the shape factor of the distribution function. If the damage variable $D$ is defined as the ratio of $N_{f}$ of material damage to the total number of elements $N$, the range is $0 \sim 1$. Then, the damage variable of rock material is

$$
\begin{aligned}
D & =\frac{N_{f}}{N}=\frac{N \int_{0}^{\varepsilon}(m / F)(x / F)^{m-1} \exp \left[-(x / F)^{m}\right] d x}{N} \\
& =1-\exp \left[-\left(\frac{\varepsilon}{F}\right)^{m}\right] .
\end{aligned}
$$

Substituting Equation (14) into Equation (11), the stressstrain relationship under uniaxial loading of mudstone can be obtained as

$$
\sigma=E \varepsilon \exp \left[-\left(\frac{\varepsilon}{F}\right)^{m}\right]
$$

The $m$ and $F$ of the damage statistical constitutive model can be determined by the peak strength point $\left(\varepsilon_{\mathrm{c}}, \sigma_{\mathrm{c}}\right)$ of the stress-strain curve under the uniaxial loading of mudstone after soaking in acid water. The slope at the peak strength point $\left(\varepsilon_{c}, \sigma_{c}\right)$ is 0 . When $\varepsilon=\varepsilon_{c}$, there are

$$
\frac{d \sigma}{d \varepsilon}=E\left[1-m\left(\frac{\varepsilon_{c}}{F}\right)^{m}\right] \exp \left[-\left(\frac{\mathcal{E}_{c}}{F}\right)^{m}\right]=0
$$

Meanwhile, the peak intensity point $\left(\varepsilon_{\mathrm{c}}, \sigma_{\mathrm{c}}\right)$ satisfies

$$
\sigma_{c}=E \varepsilon_{c} \exp \left[-\left(\frac{\varepsilon_{c}}{F}\right)^{m}\right]
$$

According to Equations (16) and (17), the following can be obtained:

$$
\begin{aligned}
& m=\left[\ln \left(E \varepsilon_{c} / \sigma_{c}\right)\right]^{-1}, \\
& F=\varepsilon_{c}\left[\ln \left(E \varepsilon_{c} / \sigma_{c}\right)\right]^{m} .
\end{aligned}
$$

In combination with Equations (12) and (15), we can obtain the constitutive damage model of mudstone soaked by segmental acid water:

$$
\sigma=\left\{\begin{array}{l}
\sigma_{A}\left(\varepsilon / \varepsilon_{A}\right)^{2}\left(\varepsilon \leq \varepsilon_{A}\right), \\
\sigma_{A}+E\left(\varepsilon-\varepsilon_{A}\right) \exp \left[-\left(\frac{\varepsilon-\varepsilon_{A}}{F}\right)^{m}\right]\left(\varepsilon \geq \varepsilon_{A}\right) .
\end{array}\right.
$$

The authors used formula (20) to do the model curve and found that the peak strength of all rock samples was lower than the experiment value. Thus, the damage variable is defined based on the fact that all the bearing capacity of the rock is lost after the failure. In fact, although the bearing 
capacity of the rock after the failure is reduced, it can still bear part of compressive stress and shear stress; that is, the rock still has residual strength after the failure. For this reason, some scholars put forward a modified damage variable characterized by critical damage value [30]:

$$
D^{\prime}=D_{u} \cdot D
$$

where $D_{u}$ is the critical loss value and $D^{\prime}$ is the modified damage variable.

$$
D_{u}=1-\sigma_{p} / \sigma_{c}
$$

where $\sigma_{p}$ is the residual strength.

It can be seen from Equation (14) that the damage variable of rock is actually related to $\exp \left[-(\varepsilon / F)^{m}\right]$. If Equation (21) is used to deduce the damage constitutive model of rock, the derivation process and the final expression will be complicated. In order to make the curve drawn by the model consistent with the experiment curve and simplify the damage constitutive model of rock. In this paper, the reciprocal of the critical damage value is substituted into Equation (17), and the revised statistical damage model of rock is

$$
\sigma_{c}=E \varepsilon_{c} \frac{1}{D_{u}} \exp \left[-\left(\frac{\mathcal{E}_{c}}{F}\right)^{m}\right] .
$$

The damage constitutive model of mudstone after acidic water corrosion can be obtained by combining Equations (12), (19), and (23):

$$
\sigma=\left\{\begin{array}{l}
\sigma_{A}\left(\varepsilon / \varepsilon_{A}\right)^{2}\left(\varepsilon \leq \varepsilon_{A}\right), \\
\sigma_{A}+E \frac{1}{D_{\mathrm{u}}}\left(\varepsilon-\varepsilon_{A}\right) \exp \left[-\frac{1}{m}\left(\frac{\varepsilon-\varepsilon_{A}}{\varepsilon_{c}-\varepsilon_{A}}\right)^{m}\right]\left(\varepsilon \geq \varepsilon_{A}\right) .
\end{array}\right.
$$

Equation (9) of compressive strength, peak strain, elastic modulus, and chemical damage parameters of mudstone soaked in acid water is substituted into Equation (18), Equations (9) and (22) are substituted into Equation (24), and the segmented damage constitutive model of mudstone soaked in acid water characterized by chemical damage parameters is obtained:

$$
\begin{aligned}
& m=\left\{\ln \left[\left(e-f D_{\mathrm{ch}}\right)\left(c+d D_{\mathrm{ch}}\right) /\left(a-b D_{\mathrm{ch}}\right)\right]\right\}^{-1}, \\
& \sigma=\left\{\begin{array}{l}
\sigma_{A}\left(\varepsilon / \varepsilon_{A}\right)^{2}\left(\varepsilon \leq \varepsilon_{A}\right), \\
\sigma_{A}+\frac{a-b D_{c h}}{a-b D_{c h}-\sigma_{p}}\left(e-f D_{c h}\right)\left(\varepsilon-\varepsilon_{A}\right) \exp \left[-\frac{1}{m}\left(\frac{\varepsilon-\varepsilon_{A}}{\varepsilon_{c}-\varepsilon_{A}}\right)^{m}\right]\left(\varepsilon \geq \varepsilon_{A}\right) .
\end{array}\right.
\end{aligned}
$$

\section{Model Verification}

Based on the results of the uniaxial loading tests and the above theoretical assumptions, a piecewise statistical constitutive damage model of mudstone soaked in acid water is established in this paper. In order to further verify the rationality of the model, the fitting curve data was used for analysis. This included the maximum stress $\sigma_{\mathrm{A}}$ and maximum strain $\varepsilon_{\mathrm{A}}$ in the compaction stage, peak strain, and residual strength of mudstone soaked in acid water that can be obtained from the measured test data. According to Figures 9-11, parameters $a=35.65, b=1175, c=0.00265, d$ $=0.839, e=9.67$, and $f=522$. The statistical constitutive parameter $m$ is calculated from Equation (25). By taking the above parameters into Equation (26), the constitutive model of piecewise statistical damage of mudstone after acid water corrosion can be calculated.

Taking rock sample $A_{1}$ as an example to illustrate how to do the curve of the model, the residual strength of rock sample $\mathrm{A}_{1}$ after failure is $5.13 \mathrm{MPa}$, the peak strain is 0.0146 , the compressive stress and strain are $6.92 \mathrm{MPa}$ and 0.00852 , respectively, and the chemical damage parameter is 0.0144 . The above parameters were substituted into Equation (25) to obtain the value of $m$ which is 1.74 , and then, all parameters were substituted into Equation (26) to obtain the piecework damage constitutive model of rock sample $A_{1}$ which is

$$
\sigma=\left\{\begin{array}{l}
6.92(\varepsilon / 0.00852)^{2}(\varepsilon \leq 0.00852), \\
6.92+\frac{35.65-1175 * 0.0144}{35.65-1175 * 0.0144-5.13}(9.67-522 * 0.0144) * 1000 * \\
(\varepsilon-0.00852) \exp \left[-\frac{1}{1.74}\left(\frac{\varepsilon-0.00852}{0.0146-0.00852}\right)^{1.74}\right](\varepsilon \geq 0.00852) .
\end{array}\right.
$$

After that, the strain data obtained by the test were substituted into Equation (27) to obtain the corresponding stress value, so as to determine the stress-strain curve of the model. Other rock samples are similar to drawing model curves. Figure 12 shows the experiment curve and model curve of the uniaxial loading of rock after soaking in acidic water. The model curve in this paper is consistent with the experimental curve, and the correlation coefficient is as high as 0.98 before the peak stress.

The traditional continuous damage constitutive model, due to the significant deviation in the initial compaction stage, leads to the poor fitting between the estimated curve 


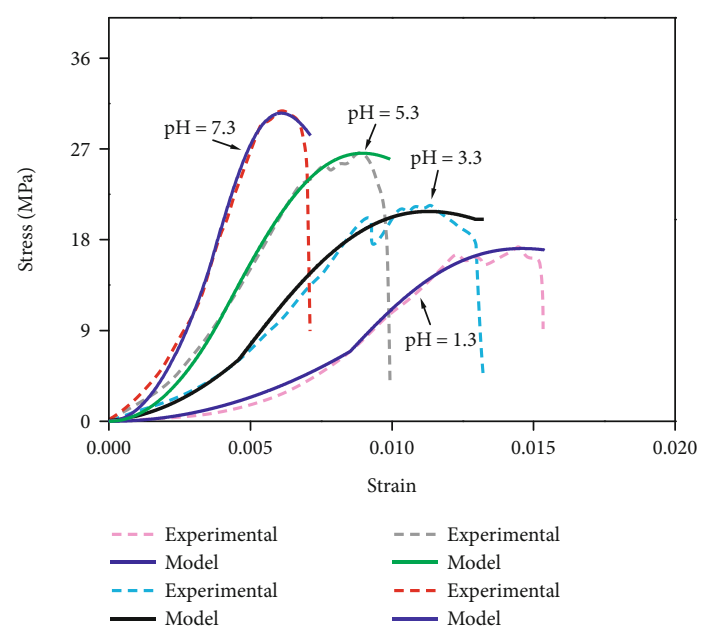

FIGURE 12: Uniaxial loading test curve and model curve of rock after acid water immersion.

and the rock stress-strain curve. The segmented statistical constitutive model of rock damage is expressed in the compaction stage and the subsequent stage separately. The advantages of the rock damage model from the elastic (linear) stage overcome the problem of a large deviation of the estimated curve from the experiment curve. Furthermore, the degree of the fitting is high and is more suitable for the analysis of rock uniaxial compression stress-strain after chemical solution corrosion.

\section{Corrosion Mechanism of Acid Water on Mudstone}

In acidic solutions, the initial $\mathrm{H}^{+}$content of the solution is relatively high. In the early stage of soaking, the water-rock chemistry is mainly the ion exchange reaction between $\mathrm{H}^{+}$ and mineral components. The reaction causes the replacement of the cation of mineral crystals, dissolution, and deterioration of mineral components. As consumption of $\mathrm{H}^{+}$and hence its depletion occurs, the water-rock chemical reaction gradually changed to mineral hydrolysis and the reaction rate slowed down. The chemical interaction between water and rock caused both physical and chemical changes in the rock specimens. In terms of physical action, the dissolution of water on the rock leads to the decrease of interparticle relay and friction and thus produces a splitting action on the micropores. In terms of chemical action, the chemical action of water and rock not only causes the change of rock mineral composition but also leads to the change of fine microstructure such as particle size and shape, pore, and fissure morphology. The combined action of these two affects finally leads to the change of physical and mechanical properties of rock. The solubility of clay mineral in the acidic solution will also be greatly increased. Feldspar solubility in the acidic solution will greatly increase, and the solubility increases with the decrease of $\mathrm{pH}$. The corrosion degree of calcite, dolomite, and other carbonate minerals increased significantly at normal pressure and temperature. During different hydrochemical solutions, minerals such as feldspar, calcite, mica, and dolomite in mudstone have the following series of chemical reactions with the $\mathrm{H}^{+}$ions in the sultions:

$$
\begin{gathered}
\mathrm{KAlSiO}_{8} \text { (feldspar) }+4 \mathrm{H}^{+}+4 \mathrm{H}_{2} \mathrm{O} \rightarrow \mathrm{K}^{+}+\mathrm{Al}^{3+}+3 \mathrm{H}_{4} \mathrm{SiO}_{4} . \\
\mathrm{KAlSiO}_{8}+8 \mathrm{H}_{2} \mathrm{O} \rightarrow \mathrm{K}^{+}+\mathrm{Al}(\mathrm{OH})_{4}{ }^{-}+3 \mathrm{H}_{4} \mathrm{SiO}_{4} . \\
\mathrm{CaCO}_{3}(\text { calcite })+2 \mathrm{H}+\rightarrow \mathrm{Ca}^{2+}+\mathrm{H}_{2} \mathrm{O}+\mathrm{CO}_{2} \uparrow . \\
\mathrm{KAl}_{3} \mathrm{Si}_{3} \mathrm{O}_{10}(\mathrm{OH})_{2}(\text { mica })+10 \mathrm{H}^{+} \rightarrow \mathrm{K}^{+}+3 \mathrm{Al}^{3+}+3 \mathrm{H}_{4} \mathrm{SiO}_{4} . \\
\mathrm{CaMg}(\mathrm{CO} 3)_{2}(\text { dolomite })+4 \mathrm{H}^{+} \rightarrow \mathrm{Ca}^{2+}+\mathrm{Mg}^{2+}+2 \mathrm{H}_{2} \mathrm{O}+2 \mathrm{CO}_{2} \uparrow .
\end{gathered}
$$

In addition to the above chemical reactions, there is also dissolution in the solution. Some minerals in the mudstone are easily soluble in the chemical solution, such as some chlorides and some oxides (iron, aluminum oxides, etc.), which are lost along with the chemical corrosion. This results in the increase of porosity of the rock and the softening of the rock structure. After the above series of hydrochemical reactions occurring between water and rocks, the reaction products were lost with the solution, resulting in the increase of porosity and softening of the sample, and some particles on the sample surface were detached. From the microscopic view, the corrosion of the hydrochemical solution to the mudstone sample causes changes in its composition and structure, which leads to an increase in its porosity. On the macro level, it is the deterioration of the mechanical characteristics of mudstone samples, which is closely related to porosity. From the analysis of the test results, it is concluded that in the process of chemical corrosion, the greater relative mass change and porosity change rate of mudstone samples, the greater the deterioration degree of rock.

\section{Conclusions}

The following are the conclusions of the research:

(1) The peak stress and elastic modulus of rock samples decrease to different degrees with the increases of solution acidity, but the peak strain increases with the increase of solution acidity, and the proportion of compaction stage increases with the increase of acidity

(2) There is a close relationship between the physical parameters of mudstone and its chemical parameters after chemical corrosion. The greater the chemical damage parameter, the greater the reduction of its mechanical parameters, and the stronger the softening effect of deformation parameters

(3) A segmental rock damage statistical constitutive model based on chemical damage parameters has been developed. This overcomes the problem of large deviation between the fitting curve and the test curve before the peak, with the correlation coefficient as high as 0.98 , which is suitable for the analysis of the uniaxial compressive stress-strain problem of rock soaked in acid water 


\section{Data Availability}

All data are given in the paper and if further data were in need, it will be provide in Annexure.

\section{Conflicts of Interest}

We declare that we do not have any commercial or associative interest that represents a conflict of interest in connection with the work submitted.

\section{Acknowledgments}

This paper was supported by the National Natural Science Foundation of China (51874280) and the Priority Academic Program Development of Jiangsu Higher Education Institutions (PAPD).

\section{References}

[1] X. Liu, C. Liu, and G. Liu, "Dynamic behavior of coalbed methane flow along the annulus of single-phase production," International Journal of Coal Science \& Technology, vol. 6, no. 4, pp. 547-555, 2019.

[2] C. Wu, C. Yuan, G. Wen, L. Han, and H. Liu, "A dynamic evaluation technique for assessing gas output from coal seams during commingling production within a coalbed methane well: a case study from the Qinshui basin," International Journal of Coal Science \& Technology, vol. 7, no. 1, pp. 122-132, 2020.

[3] W. Zhao, K. Wang, R. Zhang, H. Dong, Z. Lou, and F. An, "Influence of combination forms of intact sub-layer and tectonically deformed sub-layer of coal on the gas drainage performance of boreholes: a numerical study," International Journal of Coal Science \& Technology, 2020.

[4] A. H. Liu, Dynamic change features of water chemistry during coal reservior drainage and physical simulation of CBM desorption at fixed pressures and flow in southern qinshui basin, Chin U Min Technol, 2013.

[5] Y. Yu and L. Ma, "Application of roadway backfill mining in water-conservation coal mining: a case study in northern Shaanxi, China," Sustainability, vol. 11, no. 13, p. 3719, 2019.

[6] I. Beentjes, J. T. Bender, A. J. Hawkins, and J. W. Tester, "Chemical dissolution drilling of barre granite using a sodium hydroxide enhanced supercritical water jet," Rock Mechanics and Rock Engineering, vol. 53, no. 2, pp. 483-496, 2020.

[7] T. Al-Bazali, "A novel experimental technique to monitor the time-dependent water and ions uptake when shale interacts with aqueous solutions," Rock Mechanics and Rock Engineering, vol. 46, no. 5, pp. 1145-1156, 2013.

[8] O. Sho, Y. Hideaki, K. Naoki, C. Dae-Sung, and K. Kiyoshi, "Modeling of coupled thermal-hydraulic-mechanical-chemical processes for predicting the evolution in permeability and reactive transport behavior within single rock fractures," International Journal of Rock Mechanics and Mining Sciences, vol. 107, pp. 271-281, 2018.

[9] T. Han, J. Shi, and X. Cao, "Fracturing and damage to sandstone under coupling effects of chemical corrosion and freeze-thaw cycles," Rock Mechanics and Rock Engineering, vol. 49, no. 11, pp. 4245-4255, 2016.

[10] Y. Lin, F. Gao, K. Zhou, and R. G. Gao, "Mechanical properties and statistical damage constitutive model of rock under a coupled chemical-mechanical condition," Geofluids, vol. 2019, Article ID 7349584, 17 pages, 2019.

[11] W. Wang, X. H. Li, Q. Z. Zhu, C. Shi, and W. Y. Xu, "Experimental study of mechanical characteristics of sandy slate under chemical corrosion," Rock and Soil Mechanics, vol. 9, pp. 2559-2566, 2017.

[12] L. Tang, P. Zhang, and S. Wang, "Experimental study on the macroscopic mechanical effects of water-rock chemistry on rocks," Chinese Journal of Rock Mechanics and Engineering, vol. 21, no. 4, pp. 526-531, 2002.

[13] X. Feng and W. Ding, "Experimental study of limestone micro-fracturing under a coupled stress, fluid flow and changing chemical environment," International Journal of Rock Mechanics and Mining Sciences, vol. 44, no. 3, pp. 437-448, 2007.

[14] W. Ding, J. Chen, T. Xu, H. Chen, and H. Wang, "Study on mechanical and chemical dissolution characteristics of limestone under chemical solution erosion," Rock and Soil Mechanics, vol. 36, no. 7, pp. 1825-1830, 2015.

[15] P. Li, J. Liu, and G. Li, "Study on the influence of hydrochemistry on shear strength characteristics of sandstone," Rock and Soil Mechanics, vol. 32, no. 2, pp. 380-386, 2011.

[16] J. Xu, H. Wu, L. Cheng, J. Liu, and W. Zhou, "Experimental study on shear failure characteristics of sandstone under acidic conditions," Chinese Journal of Rock Mechanics and Engineering, vol. 31, no. 2, pp. 3898-3903, 2012.

[17] T. Han, Y. Chen, J. Shi, C. Yu, and M. He, "Experimental study on the influence of hydrochemical corrosion on mechanical properties of sandstone," Chinese Journal of Rock Mechanics and Engineering, vol. 32, no. 2, pp. 3065-3072, 2013.

[18] H. P. Kang, "The damage of water to rock," Hydrogeology and Engineering Geology, vol. 3, pp. 39-41, 1994.

[19] X. Hu, B. Hong, and Y. Meng, "Statistical damage model of red sandstone with effect of water ratio considered," Journal of China University of Mining and Technology, vol. 36, no. 5, pp. 609-613, 2007.

[20] E. Zhang, G. Yang, L. Tang, Q. Yang, and Z. Xie, "Study on influence of water content to damage and degradation laws of argillaceous siltstone," Coal Science \& Technology, vol. 47, no. 2, pp. 19-25, 2019.

[21] Y. L. Chen, W. Shao, and Y. C. Zhou, "The elastoplastic damage constitutive model of water saturated concrete under uniaxial compression," Engineering Mechanics, vol. 28, no. 11, pp. 59-063, 2011.

[22] H. Wang, T. H. Yang, H. L. Liu, and Y. C. Zhao, "Deformation and acoustic emission characteristics of dry and saturated sandstone under cyclic loading," Journal of Northeast Normal University(Natural Science Edition), vol. 37, p. 1165, 2016.

[23] X. F. Li, H. B. Li, L. W. Liu, Y. Q. Liu, M. H. Ju, and J. Zhao, "Investigating the crack initiation and propagation mechanism in brittle rocks using grain-based finite-discrete element method," International Journal of Rock Mechanics and Mining Sciences, vol. 127, p. 104219, 2020.

[24] C. D. Martin and N. A. Chandler, "The progressive fracture of Lac du Bonnet granite," International Journal of Rock Mechanics and Mining Sciences, vol. 31, no. 6, pp. 643659, 1994.

[25] G. K. Zhang, H. B. Li, M. Y. Wang, and X. F. Li, "Crack initiation of granite under uniaxial compression tests: a comparison study," Journal of Rock Mechanics and Geotechnical Engineering, vol. 12, no. 3, pp. 656-666, 2020. 
[26] J. Lemaitre, "How to use damage mechanics," Nuclear Engineering and Design, vol. 80, no. 2, pp. 233-245, 1984.

[27] Z. D. Lu, Experimental an theoretical analysis on mechanical properties of fractured rock under water-rock interaction, Institute of Rock and Soil Mechanics, Wuhan, 2010.

[28] J. A. Sanchidrián, F. Ouchterlony, P. Segarra, and P. Moser, "Size distribution functions for rock fragments," International Journal of Rock Mechanics and Mining Sciences, vol. 71, pp. 381-394, 2014.

[29] K. Shin, K. Sugawara, and S. Okubo, "Application of weibull's theory to estimating in situ maximum stress $\sigma_{\mathrm{H}}$ by hydrofracturing," International Journal of Rock Mechanics and Mining Sciences, vol. 38, no. 3, pp. 413-420, 2001.

[30] Y. R. Zhang, C. J. Deng, and J. L. Wang, "The study of slip line field and upper bound method based on the non- associated flow rule," Engineering and Science, vol. 12, no. 8, pp. 56-69, 2010. 